\title{
Couinaud Liver Segment
}

National Cancer Institute

\section{Source}

National Cancer Institute. Couinaud Liver Segment. NCI Thesaurus. Code C79730.

Any of the eight liver segments that has its own vascular inflow, outflow, and biliary drainage, thus defined as functionally independent. 